SYNLETT Spotlight 27

This feature focuses on a reagent chosen by a postgraduate, highlighting the uses and preparation of the reagent in current research

\section{Phenylselenotrimethylsilane: PhSeTMS}

Compiled by Marc David

Ecole Superieure de Physique et Chimie Industrielles de Paris, 10 rue Vauquelin, Laboratoire de Chimie Organique, 75231 Paris Cedex 05, France

$\mathrm{PhD}$ under the supervision of Pr. G. Lhommet at the Université Pierre et Marie Curie, Paris, France.

Currently in postdoc in Pr. J. Cossy's laboratory at the Ecole Superieure de Physique et Chimie Industrielles, France.

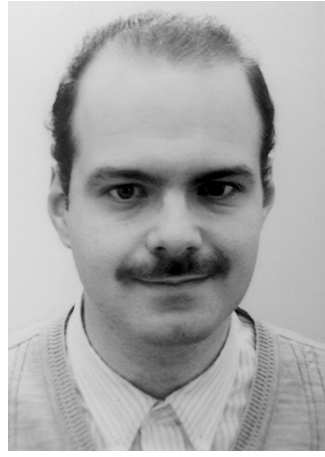

Organoselenium compounds are useful intermediates in organic synthesis. For example $\beta$-elimination of selenoxides and radical fission reaction of a carbon-selenium bond are now frequently employed reactions in the total synthesis of natural products. Phenylselenotrimethylsilane (PSTMS), which had been synthesized some years $\mathrm{ago}^{1}$ is one of the best and readily available reagents that allow the introduction of selenium atoms in a molecule. The nucleophilic site is obviously the selenium atom and sometimes the phenylselenolate is formed in situ. ${ }^{2}$

Preparation: PSTMS is now commercially available but can also be synthesized by different methods. In general, phenylselenolate is generated by different ways and quenched by trimethylsilyl chloride. It can be obtained using:
- a Grignard reagent ${ }^{3}$

$\mathrm{PhMgBr}+\mathrm{Se} \longrightarrow \mathrm{PhSeMgBr} \stackrel{\text { TMSCl }}{\longrightarrow}$ PhSeTMS

- sodium metal ${ }^{4}$

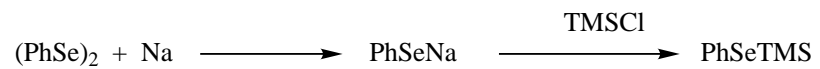

- methyl lithium ${ }^{5}$

$\mathrm{PhSeH}+\mathrm{MeLi} \longrightarrow$ PhSeLi $\stackrel{\text { TMSCl }}{\longrightarrow}$ PhSeTMS

\title{
Abstracts
}

In order to prepare the chromophore component of Neocarzinostatin, a potent antitumor agent, Myers and al. ${ }^{6}$ have used PSTMS to introduce a protected aldehyde on a double bond in one step with a good yield.
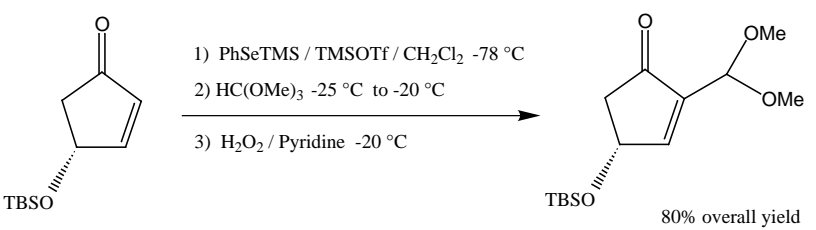

Selenoesters, which are activated forms of carboxylic acids, are readily prepared by using PSTMS in the presence of samarium iodide, ${ }^{7}$ which leads to the formation of the samarium phenylselenolate. This specie reacts smoothly with various acyl chlorides to afford the corresponding selenoesters in very good yields.
Direct conversion of benzylic hydroxy groups into $\alpha$-phenylseleno toluenes have been recently achieved ${ }^{8}$ using PSTMS in dichloromethane in the presence of aluminum tribromide under mild conditions.

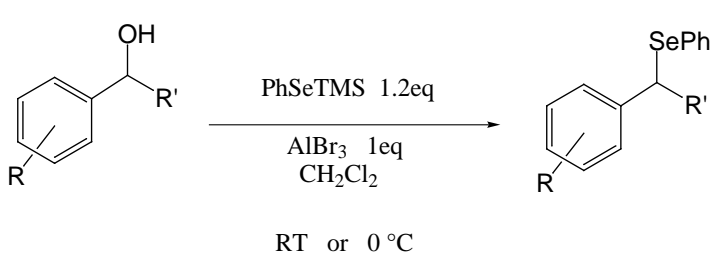

$\mathrm{R}=\mathrm{H}, \mathrm{Me}, \mathrm{OMe}, \mathrm{Cl}$

$\mathrm{R}^{\prime}=$ alkyls

\section{References and Notes}

(1) Derkach, N. Y.; Pasmurtseva, N. A.; Levchenko, E. S. J. Org. Chem. USSR (Engl. Transl.) 1971, 7, 1600.

(2) Detty, M.R. Tetrahedron Lett. 1978, 21, 5087.

(3) Schmidt, M.; Kiewert, E.; Lux, H.; Sametschek, C. Phosphorus Sulfur Relat. Elem. 1986, 26, 163.

(4) (a) Detty, M. R. J. Org. Chem. 1979, 44, 4528.

(b) Miyoshi, N.; Ishii, H.; Kondo, K.; Murai, S.; Sonoda, N. Synthesis 1979, 300.
(5) Liotta, D.; Paty, P. B.; Johnston, J.; Zima, G. Tetrahedron Lett. 1978, 21, 5091.

(6) Myers, A. G.; Hammond, M.; Wu, Y.; Xiang, J. N.; Harrington, P. M.; Kuo, E. Y. J. Am. Chem. Soc. 1996, 118, 10006.

(7) Zhang, S.; Zhang, Y. Synth. Comm. 1998, 28, 3999.

(8) Abe, H.; Yamasaki, A.; Harayama, T. Chem. Pharm. Bull. 1998, 46, 1313.

Article Identifier:

1437-2096,E;2001,0,03,0445,0445,ftx,en;V02400ST.pdf 